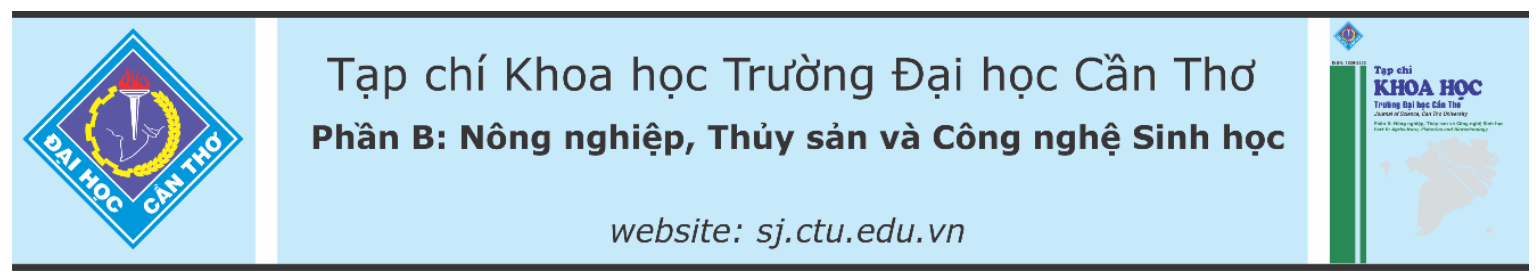

DOI:10.22144/ctu.jvn.2021.048

\title{
ẢNH HƯởNG THAY THẾ TẢo Chlorella SP. BÀ̀NG MEN BÁNH MÌ Saccharomyces cerevisiae LÊN TĂNG TRỬ̉NG QUẦN THỂ LUÂN TRÙNG Brachionus calyciflorus
}

\author{
Huỳnh Thanh Tới ${ }^{*}$ Huỳnh Thị Ngọc Hiền, Vũ Hùng Hải, Âu Văn Hóa, Trần Trung Giang và \\ Nguyễn Thị Hồng Vân
}

Khoa Thủy sản, Truờng Đại học Cần Tho

*Nguoòi chịu trách nhiệm về bài viết: Huỳnh Thanh Tới (email: httoi@ctu.edu.vn)

\section{Thông tin chung:}

Ngày nhận bài: 02/10/2020

Ngày nhận bài sủa: 11/11/2020

Ngày duyệt đăng: 28/04/2021

\section{Title:}

Effect of replacement of Chlorella sp. with Baker's yeast Saccharomyces cerevisiae on population growth of Rotifer Brachionus calyciflorus

\section{Tù khóa:}

Brachionus calyciflorus, Chlorella sp., luân trùng, men bánh mì

\section{Keywords:}

Baker's yeast, Brachionus calyciflorus, Chlorella sp., rotifer

\begin{abstract}
The study was conducted with two experiments to assess the effect of feeding ration of Chlorella sp. and the effect of replacement of Chlorella sp. with baker's yeast on the population growth of Brachionus calyciflorus as follows: experiment 1 consisted five treatments, rotifers fed with microalgae increased a cumulative 20,000 cells/rotifer/day per treatment derived from 60,000 cells/rotifer/day. Based on the results of experiment 1 , the suitable microalgae feeding ration with good results on rotifer population growth was selected for the next experimental setup. Experiment 2 was arranged with microalgae ration replaced by Baker's yeast, the substitutes increased by $25 \%$ from second treatment to last one corresponding to the reduction of microalgae, each treatment with 3 replications. Rotifer was stocked at an initial density of 200 rotifers $/ m L$. The results showed that the highest density of rotifers was 688 rotifers $/ \mathrm{mL}$ on day 4 at the treatment of 80.000 cells/ rotifer/day, and reached 898 rotifer/mL at treatments of $75 \%$ Chlorella $+25 \%$ Baker's yeast after 5 days of rearing. The results indicated that replacing $25 \%$ of algae with Baker's yeast improved the density of B. calyciflorus.
\end{abstract}

\section{TÓM TẮT}

Nghiên cứu được thực hiện với 2 thí nghiệm nhằm đánh giá ảnh hưởng của liều lương tảo Chlorealla sp. và ảnh hưởng của thay thế tảo với men bánh mì lên sụ tăng truởng của luân trùng Brachionus calyciflorus nhu sau: thí nghiệm 1 gồm 5 nghiệm thức, luân trùng được cho ăn bằng tảo tăng lũy tuyến 20.000 tế bào/luân trùng/ngày cho mối nghiệm thiúc xuất phát tùi 60.000 tế bào/luân trùng/ngày. Dưa vào kết quả của thí nghiệm 1, mật độ tảo cho kết quả tốt về tăng trưởng quần thể được chọn để tiến hành bố trí thi nghiệm tiếp theo, thi nghiệm 2 được bố trí với số luợng tảo được thay thế bằng men bánh mì, số luợng thay thế tăng 25\% tù nghiệm thức thứ 2 đến nghiệm thức cuối tuoong ưng với lương tảo giảm, mỗi nghiệm thức với 3 lần lặp lại. Luân trùng được thả nuôi với mật độ ban đầu là 200 luân trùng/mL. Kết quả cho thấy, mật độ luân trùng đạt cao nhất ở nghiệm thíc cho ăn 80.000 tế bào/luân trùng/ngày vào ngày thú 4 là 688 luân trùng $/ m L$ và đạt 898 luân trùng $/ m L$ ớ nghiệm thức cho ăn $75 \%$ tảo $+25 \%$ men bánh mì sau 5 ngày nuôi. Tù̀ kết quả thí nghiệm khẳng định rằng thay thế $25 \%$ tảo bằng men bánh mì có cải thiện tăng trưởng quần thể của B. calyciflorus. 


\section{GIỚI THIỆU}

Trong vài thập nên gần đây, luân trùng được sử dụng như một nguồn thức ăn tươi sống cho ấu trùng cá và giáp xác vì có kích thước nhỏ $(100-300 \mu \mathrm{m})$, bơi lội chậm chạp, sống lơ lửng trong nước, đặc biệt luân trùng là loài ăn lọc không chọn lọc (thức ăn <20 $\mu \mathrm{m})$ nên luân trùng có thể được giàu hóa bằng các chất dinh dưỡng cần thiết hay kháng sinh để đưa vào cơ thể ấu trùng. Trong kỹ thuật nuôi luân trùng thì thức ăn cho chúng có thể sử dụng nhiều loại khác nhau như: tảo, men bánh mì, thức ăn nhân tạo,... Luân trùng (cả loài nước ngọt và lợ) đều phát triển tốt nhất khi nuôi bằng tảo Chlorella $\mathrm{sp}$., nhưng tốn diện tích và chi phí nuôi cấy tảo (Trần Sương Ngọc và ctv., 2017). Bên cạnh việc sử dụng tảo tươi và tảo khô, người nuôi còn sử dụng men bánh mì làm thức ăn cho luân trùng, do men bánh mì dễ cho ăn và rẻ tiền. Komis (1992) cho rằng men bánh mì có thể thay tảo, nhưng nếu nuôi luân trùng hoàn toàn bằng men bánh mì thì năng suất không ổn định và quần thể mau tàn, giá trị dinh dưỡng thấp. Khi cho ăn bằng men bánh mì thì rất khó xử lý thức ăn dư thừa, điều này dễ nhận biết do thành bể nuôi có độ nhớt cao, nước có mùi hôi và thức ăn đóng thành hạt lớn trôi nổi trong nước.

Luân trùng Brachionus calyciflorus có kích cỡ tương đối lớn $185 \mu \mathrm{m}$ (Stevenson et al., 1998), chứa $77,8 \%$ protein, $15,7 \%$ lipid, $27,8 \%$ carbohydrate và 71,2\% nước (Arak et al., 2014), bơi lội chậm (0,2$0,3 \mathrm{~mm} /$ giây) (Chen et al., 2014), vì thế chúng là loại thức ăn tươi sống khá lý tưởng cho ấu trùng thủy sản nước ngọt, nên chúng đã được nghiên cứu làm thức ăn cho ấu trùng cá cảnh (Lim \& Wong, 1997), cá trê phi Clarias gariepinus (Awaiss \& Kestemont, 1998), cá tầm Ba Tư Acipenser persicus (Rufchaie et al., 2012)... Luân trùng $B$. calyciflorus được nuôi sinh khối với 03 loại thức ăn riêng biệt gồm tảo Chlorella, Spirulina và men bánh mì Saccharmyces cerevisiae (Rajendiran \& Subramanian, 2007), nhưng quần thể luân trùng phát triển tốt khi ăn tảo Chlorella. Mặc dầu luân trùng nước ngọt không thể phát triển tốt với thức ăn hoàn toàn bằng men bánh mì nhưng khi kết hợp với tảo Chlorella thì sẽ cho kết quả tăng trưởng quần thể tốt hơn cho ăn bằng men bánh mì, điều này đã được minh chứng trên luân trùng Brachionus angularis (Trần Sương Ngọc, 2012). Nhưng đến nay, việc kết hợp tảo với men bánh mì trong nuôi sinh khối luân trùng $B$. calyciflorus vẫn chưa được nghiên cứu, do đó nghiên cứu được thực hiện nhằm tìm ra mật độ tảo và tỷ lệ kết hợp giữa tảo và men bánh mì thích hợp để đạt tăng trưởng quần thể luân trùng cao nhất.

\section{VậT LIỆU VÀ PHƯỚNG PHÁP NGHIÊN CÚU}

\subsection{Vật liệu nghiên cứu}

Dụng cụ và trang thiết bị thí nghiệm bao gồm 30 keo nhựa $10 \mathrm{~L}$, thùng nhựa, xô nhựa, ca nhựa, lưới lọc có các kích thước mắt lưới khác nhau $(50 \mu \mathrm{m}$ và $300 \mu \mathrm{m}$ ), kính lúp, máy đo pH, nhiệt độ, hệ thống sục khí,...

\subsection{Nguồn nước}

Nguồn nước ngọt được lấy từ sông Bún Xáng (Cần Thơ) được lọc qua túi lọc có mắt lưới $25 \mu \mathrm{m}$ và nước được xử lý bằng chlorine với nồng độ 50 $\mathrm{mg} / \mathrm{L}$, sục khí mạnh trong 04 ngày sau đó thử độ tồn dư của chlorine bằng thuốc thử KI. Nước được trung hòa bằng dung dịch $\mathrm{Na}_{2} \mathrm{~S}_{2} \mathrm{O}_{3}(158,11 \mathrm{~g} / \mathrm{L}$ nước $)$ khi kiểm tra còn tồn dư chlorine trước khi sử dụng.

\subsection{Thức ăn}

Tảo Chlorella sp. được cung cấp từ phòng thí nghiệm thức ăn tự nhiên, bộ môn Thủy Sinh học ứng dụng, Khoa Thủy sản, Trường Đại học Cần Thơ. Men bánh mì hiệu SAF - Instant (sản xuất tại Pháp) được mua tại cửa hàng sản xuất bánh mì tại thành phố Cần Thơ.

\subsection{Nguồn gốc luân trùng}

Luân trùng giống được cung cấp từ phòng thí nghiệm thức ăn tự nhiên, bộ môn Thủy sinh học ứng dụng, Khoa Thủy sản, Trường Đại học Cần Thơ.

\subsection{Bố trí thí nghiệm}

Thí nghiệm 1: Ảnh hưởng mật độ tảo lên tăng trưởng quần thể luân trùng $B$. calyciflorus

Luân trùng $B$. calyciflorus được nuôi mẻ trong keo nhựa $10 \mathrm{~L}$ chứa $8 \mathrm{~L}$ nước. Mật độ luân trùng ban đầu là 200 luân trùng $/ \mathrm{mL}$. Luân trùng được cho ăn hoàn toàn bằng tảo Chlorella sp. với mật độ 60.000 , $80.000,100.000,120.000$ và 140.000 tb/luân trùng/ngày, tương ứng với 05 nghiệm thức $(\mathrm{NT})$, mỗi nghiệm thức được lặp lại 03 lần, như sau:

NT1(60): cho ăn bằng tảo với mật độ 60.000 tb/luân trùng /ngày

NT2(80): cho ăn bằng tảovới mật độ 80.000 tb/luân trùng /ngày

NT4(100): cho ăn bằng tảo với mật độ 100.000 tb/luân trùng/ngày

NT4(120): cho ăn bằng tảo với mật độ 120.000 tb/luân trùng/ngày

NT5(140): cho ăn bằng tảo với mật độ 140.000 tb/luân trùng/ngày 
Thí nghiệm được thực hiện trong phòng có điều chỉnh nhiệt độ $\left(23^{\circ} \mathrm{C}\right)$. Chế độ thay nước là 25\%/ngày (Trần Sương Ngọc, 2012). Thí nghiệm kết thúc khi mật độ luân trùng giảm liên tục 2 ngày.

Thí nghiệm 2: Ảnh hưởng thay thế tảo bằng mem bánh mì lên tăng trưởng quần thể luân trùng $B$. calyciflorus

Dựa vào kết quả của thí nghiệm 1 , khẩu phần ăn với mật độ tảo 80.000 tb/luân trùng/ngày được chọn để tiến hành bố trí thí nghiệm 2 với thay thế tảo bằng men bánh mì (tính theo số lượng tế bào). Trong thí nghiệm 2, luân trùng $B$. calyciflorus được nuôi mẻ trong keo nhựa $10 \mathrm{~L}$ chứa $8 \mathrm{~L}$ nước sông đã qua xử lý diệt tạp bằng chlorine $50 \mathrm{mg} / \mathrm{L}$. Mật độ luân trùng ban đầu là 200 luân trùng $/ \mathrm{mL}$. Thí nghiệm được thực hiện trong phòng có điều chỉnh nhiệt độ $\left(23^{\circ} \mathrm{C}\right)$, chế độ thay nước là $25 \% /$ ngày. Luân trùng được cho ăn $100 \%$ tảo ở nghiệm thức đối chứng và giảm dần $25 \%$ tảo theo mỗi nghiệm thức tiếp theo và thay thế bằng lượng men bánh mì tương ứng với lượng tảo giảm, thí nghiệm gồm 5 nghiệm thức, mỗi nghiệm thức được lặp lại 03 lần, như sau:

NT1 (100T): cho ăn với tỉ lệ 100\% tảo

NT2 (75T): cho ăn với tỉ lệ $75 \%$ tảo $+25 \%$ men bánh mì

NT3 (50T): cho ăn với tỉ lệ 50\% tảo + 50\% men bánh mì

NT4 (25T): cho ăn với tỉ lệ $25 \%$ tảo $+75 \%$ men bánh mì

NT5 (0T): cho ăn với tỉ lệ 100\% men bánh mì

Thí nghiệm kết thúc khi mật độ luân trùng (luân trùng $/ \mathrm{mL}$ ) giảm liên tục 2 ngày.

\section{Chăm sóc và quản lý}

Nước nuôi luân trùng được thay mới mỗi ngày, mỗi lần thay $25 \%$ thể tích (Trần Sương Ngọc, 2012) bằng cách sử dụng ống lọc lưới có kích thước mắt lưới $50 \mu \mathrm{m}$, ống lọc được đưa vào keo nuôi luân trùng và dùng ông hút hút phần nước đã lọc nằm phía trong ống lọc ra ngoài, sau đó nước mới (không chứa chlorine) được bổ sung để đảm bảo bằng với thể tích ban đầu.

\section{Chuẩn bị thức ăn và cho ăn}

Tảo Chlorella sp. từ phòng nuôi cấy tảo được thu hoạch bằng máy ly tâm (3.000 vòng/phút), sau đó được trữ ở $4{ }^{\circ} \mathrm{C}$ để sử dụng cho quá trình thí nghiệm.

Men bánh mì được làm xay mịn trong máy sinh tố với tỉ lệ $50 \mathrm{~g} / \mathrm{L}$ nước và thêm $2 \mathrm{~mL}$ DHA Selco
(INVE, Bỉ) trong thời gian 1-2 phút và được bảo quản trong tủ lạnh ở $4{ }^{\circ} \mathrm{C}$.

Phần trăm giữa tảo và men được tính toán dựa vào mật độ tế bào. Số lượng tảo trong khẩu phần ăn trong ngày được chia làm 02 lần cho ăn và số lượng men bánh mỳ trong khẩu phần ăn trong ngày được chia làm 08 lần cho ăn.

\section{Xác định mật độ tảo và men bánh mì}

Mật độ tảo và men bánh mỳ được xác định bằng buồng đếm hồng cầu Burker. Trước tiên, buồng đếm Burker được rửa sạch và lau khô bằng giấy, buồng đếm được đậy kín bằng lamelle và mẫu tảo hoặc men bánh mì được lấy bằng micropipette và nhỏ vào buồng đếm (nếu mẫu tảo quá dày thì tiến hánh pha loãng). Sau đó, quan sát tảo hoặc men dưới kíp hiển vi với độ phóng đại $40 \mathrm{X}$, và số lượng tảo trong 20 ô vuông của buống đếm theo 02 đường chéo đã được xác định. Mỗi mẫu tảo và men được đếm 02 lần, sau đó mật độ tảo và men được tính toán bằng công thức sau:

Số tế bào tảo hay men bánh $\mathrm{mì} / \mathrm{mL}=\left(\left(\mathrm{n}_{1+} \mathrm{n}_{2}\right) / 160\right.$ $\times 10^{6} \times \mathrm{d}$

Trong đó:

$\mathrm{n}_{1:}$ Số tế bào tảo ở buồng đếm thứ nhất

$\mathrm{n}_{2}$ : Số tế bào tảo ở buồng đếm thứ hai

d: hệ số pha loãng

\subsection{Thu thập và tính toán số liệu}

Nhiệt độ, pH nước: được đo 1 ngày/lần vào lúc 8:00 giờ và đo bằng máy đo nhiệt độ, $\mathrm{pH}$ hiệu Hanna. Mẫu nước xác định hàm lượng TAN $\left(\mathrm{NH}_{3} / \mathrm{NH}_{4}{ }^{+}\right)$được thu 3 ngày/lần và phân tích theo phương pháp Indophenol Blue và $\mathrm{NO}_{2}^{-}$được phân tích theo phương pháp Diazonium tại phòng phân tích chất lượng nước thuộc bộ môn Thủy sinh học ứng dụng, Khoa Thủy sản, Trường Đại học Cần Tho.

Mật độ luân trùng (luân trùng $/ \mathrm{mL}$ ) được xác định vào mỗi buổi sáng bằng cách thu $0,2 \mathrm{~mL}$ mẫu, sau đó cố định bằng dung dịch Lugol và đếm dưới kính lúp (4X), không đếm những luân tùng không bắt màu Lugol (luân trùng chết), sau đó mật độ luân trùng được tính toán như sau:

Mật độ (luân trùng $/ \mathrm{mL}$ ) = số luân trùng đếm được $\times 5$

Tốc độ tăng trưởng quần thể/ngày của luân trùng được tính theo công thức: 
K = Ln(mật độ luân trùng cuối) - Ln(mật độ luân trùng lúc thả nuôi)/thời gian nuôi

\subsection{Xử lý thống kê}

Số liệu đã thu thập được tính toán trung bình và độ lệch chuẩn bằng phần mềm Excel, sau đó được so sánh sai khác có ý nghĩa thống kê $(p<0,05)$ giữa các nghiệm thức bằng phép thử Tukey, phần mềm Statistica 6.0.

\section{KẾT QUẢ VÀ THẢO LUẬN}

\section{1. Ảnh hưởng mật độ tảo Chlorella sp. lên tăng trưởng quần thể luân trùng $B$. calyciflorus}

\subsubsection{Các yếu tố môi trường}

Nhiệt độ trung bình giữa các NT trong thời gian dao động $24,7^{\circ} \mathrm{C}-24,8^{\circ} \mathrm{C}$ và $\mathrm{pH}$ dao động là 8,3 8,4 (Bảng 1 ). Luân trùng $B$. calyciflorus là loài khá rộng nhiệt khoảng nhiệt độ thích hợp cho sự phát triển của luân trùng từ $24^{\circ} \mathrm{C}$ dến $35^{\circ} \mathrm{C}$. Theo Kauler and Enesco (2011), nhiệt độ môi trường ảnh hưởng khá lớn đến giai đoạn tiền sinh sản, hậu sinh sản, tuổi thọ cũng như số lượng con non, ở loài $B$. calyciflorus sinh sản con non trong vòng đời ở nhiệt độ $29^{\circ} \mathrm{C}$ cao hơn nuôi ở nhiệt độ dưới $22^{\circ} \mathrm{C}$. Theo
Mitchell (1992), luân trùng $B$. calyciflorus có thể sống ở $\mathrm{pH}$ từ 2,5-11,5, nhưng tăng trưởng âm ở $\mathrm{pH}$ từ 5,5-6,5 và tăng trưởng dương ở $\mathrm{pH}$ từ 7,5-10,5, do vậy $\mathrm{pH}$ nước của thí nghiệm hiện tại vẫn nằm trong khoảng thích hợp cho sự phát triển quần thể của luân trùng $B$. calyciflorus.

Hàm lượng TAN tích tụ khá nhiều vào cuối chu kỳ thí nghiệm, dao động từ $0,49-1,31 \mathrm{mg} / \mathrm{L}$ vào ngày nuôi thứ 7 (Bảng 1). Hàm lượng TAN tăng dần theo số lượng tảo tăng trong khẩu phần ăn, cao nhất ở nghiệm thức NT1 (140) nghiệm thức cho ăn 140.000 tb tảo/luân trùng/mL là $1,31 \mathrm{mg} / \mathrm{L}$, nguyên nhân có thể do chất thải từ luân trùng. Theo Liang et al. (2019), hàm lượng ammonia trong nước nuôi trên $1,6 \mathrm{mg} / \mathrm{L}$ đã gây ảnh hưởng đến khả năng tăng trưởng của quần thể. Do vậy, hàm lượng TAN ở thí nghiệm hiện vẫn còn dưới mức gây ảnh hưởng phát triển của luân trùng.

Nồng độ $\mathrm{NO}_{2}{ }^{-}$dao động từ $0,05-0,13 \mathrm{mg} / \mathrm{L}$ trong quá trình nuôi (Bảng 1). Chen et al. (2011) cho rằng luân trùng $B$. calyciflorus bị ức chế tăng trưởng khi hàm lượng $\mathrm{NO}_{2}^{-}$tăng lên $10 \mathrm{mg} / \mathrm{L}$, do đó hàm lượng $\mathrm{NO}_{2}{ }^{-}$ở thí nghiệm hiện tại không ảnh hưởng đến tăng trưởng của luân trùng.

Bảng 1. Các yếu tố môi trường ở thí nghiệm luân trùng Brachionus calyciflorus cho ăn bằng tảo với các mật độ khác nhau

\begin{tabular}{|c|c|c|c|c|c|c|}
\hline \multicolumn{2}{|c|}{ Nghiệm thức } & NT1(60) & NT2(80) & NT3(100) & NT4(120) & NT5(140) \\
\hline \multicolumn{2}{|c|}{ Nhiệt độ $\left({ }^{\circ} \mathrm{C}\right)$} & $24,8 \pm 0,2$ & $24,7 \pm 0,1$ & $24,7 \pm 0,1$ & $24,7+0,2$ & $24,8 \pm 0,2$ \\
\hline \multicolumn{2}{|l|}{$\mathrm{pH}$} & $8,4 \pm 0,0$ & $8,4 \pm 0,1$ & $8,4 \pm 0,1$ & $8,4 \pm 0,0$ & $8,3 \pm 0,1$ \\
\hline \multirow{2}{*}{$\begin{array}{l}\text { TAN } \\
(\mathrm{mg} / \mathrm{L})\end{array}$} & Ngày 3 & $0,14 \pm 0,01$ & $0,14 \pm 0,04$ & $0,36 \pm 0,53$ & $0,86 \pm 00,7$ & $1,15 \pm 0,34$ \\
\hline & Ngày 6 & $0,49 \pm 0,18$ & $0,74 \pm 0,30$ & $0,88 \pm 0,04$ & $1,17 \pm 0,10$ & $1,31 \pm 0,12$ \\
\hline \multirow{2}{*}{$\begin{array}{l}\mathrm{NO}_{2}^{-} \\
(\mathrm{mg} / \mathrm{L})\end{array}$} & Ngày 3 & $0,05 \pm 0,02$ & $0,07 \pm 0,02$ & $0,06 \pm 0,01$ & $0,05 \pm 0,01$ & $0,09 \pm 0,01$ \\
\hline & Ngày 6 & $0,13 \pm 0,02$ & $0,12 \pm 0,01$ & $0,08 \pm 0,03$ & $0,08 \pm 0,01$ & $0,09 \pm 0,01$ \\
\hline
\end{tabular}

\subsubsection{Mật độ phát triển của luân trùng}

Mật độ luân trùng tăng dần trong quá trình nuôi và đạt cao nhất ở ngày nuôi thứ 4 sau đó giảm dần vào các ngày cuối của chu kỳ thí nghiệm (Bảng 2).

Bảng 2. Biến động mật độ (luân trùng/mL) giữa các nghiệm thức cho ăn bằng tảo

\begin{tabular}{crrrrr}
\hline Ngày nuôi & NT1 (60) & NT2 (80) & NT3 (100) & NT4 (120) & NT5 (140) \\
\hline 1 & $200 \pm 0$ & $200 \pm 0$ & $200 \pm 0$ & $200 \pm 0$ & $200 \pm 0$ \\
2 & $243 \pm 23^{\mathrm{a}}$ & $270 \pm 42^{\mathrm{a}}$ & $249 \pm 45^{\mathrm{a}}$ & $292 \pm 24^{\mathrm{a}}$ & $235 \pm 30^{\mathrm{a}}$ \\
3 & $324 \pm 57^{\mathrm{a}}$ & $554 \pm 78^{\mathrm{b}}$ & $459 \pm 27^{\mathrm{ab}}$ & $477 \pm 69^{\mathrm{ab}}$ & $368 \pm 49^{\mathrm{a}}$ \\
4 & $500 \pm 50^{\mathrm{a}}$ & $688 \pm 71^{\mathrm{b}}$ & $623 \pm 65^{\mathrm{ab}}$ & $582 \pm 10^{\mathrm{ab}}$ & $505 \pm 102^{\mathrm{a}}$ \\
5 & $481 \pm 31^{\mathrm{b}}$ & $554 \pm 68^{\mathrm{b}}$ & $530 \pm 174^{\mathrm{b}}$ & $386 \pm 99^{\mathrm{ab}}$ & $162 \pm 46^{\mathrm{a}}$ \\
6 & $441 \pm 96^{\mathrm{b}}$ & $278 \pm 79^{\mathrm{ab}}$ & $341 \pm 136^{\mathrm{ab}}$ & $184 \pm 66^{\mathrm{a}}$ & $137 \pm 47^{\mathrm{a}}$ \\
7 & $301 \pm 77^{\mathrm{a}}$ & $249 \pm 55^{\mathrm{a}}$ & $189 \pm 92^{\mathrm{a}}$ & $147 \pm 11^{\mathrm{a}}$ & $133 \pm 83^{\mathrm{a}}$ \\
\hline
\end{tabular}

Ghi chú: các kí tụ mũ trong cùng hàng có chũ cái khác nhau thì khác biệt có ý nghĩa thống kê (p<0,05). Giá trị trên thể hiện số trung bình và độ lệch chuẩn.

Kết quả trình bày ở Bảng 2 cho thấy trong các khẩu phần ăn thì mật độ luân trùng NT4(120) cho ăn
120.000 tb/luân trùng/ngày đạt cao nhất (292 luân trùng $/ \mathrm{mL}$ ) vào ngày nuôi thứ 2 , nhưng cao hơn không có ý nghĩa thống kê $(\mathrm{p}>0,05)$ so với các 
nghiệm thức còn lại. Từ ngày nuôi thứ 03 đến ngày nuôi thứ 5 thì mật độ luân trùng ở nghiệm thức NT2(80) cho ăn tảo 80.000 tb/luân trùng/ngày đạt mật độ cao nhất, cao hơn có ý nghĩa thống kê $(\mathrm{p}<0,05)$ so với các nghiệm thức $\mathrm{NT1}(60)$ và T5(140), nhưng không cao nghiệm thức NT1(60) ở ngày nuôi thứ 5 . Nhìn chung, mật độ luân trùng giảm khi lượng tảo càng tăng (tính từ 80.000 tb/luân trùng/ngày trở lên). Lucía-Pavón et al. (2001) báo cáo rằng luân trùng $B$. calyciflorus tăng trưởng quần thể khi cho ăn bằng tảo Chlorella vulgaris với mật độ $4,5 \times 10^{6}$ tế bào/mL tốt hơn cho ăn với mật độ 0,5 $\mathrm{x} 10^{6}$ tế bào $/ \mathrm{mL}$. Theo Trần Sương Ngọc và ctv. (2010), mật độ tảo cho ăn quá nhiều thì tăng trưởng chậm, luân trùng tăng trưởng quần thể tốt nhất khi được cung cấp tảo với liều lượng thích hợp, điều này đã được chứng minh trên luân trùng Brachionus angularis.

3.1.3. Tốc độ tăng truởng quần thể của luân trùng

Tốc độ tăng trưởng quần thể (Bảng 3) của luân trùng ở nghiệm thức NT2(80) cho ăn 80.000 tb/luân trùng/ngày, cao hơn tốc độ tăng trưởng quần thể của các nghiệm thức còn lại, ngoại trừ ngày nuôi thứ 02 thấp hơn không có ý nghĩa thống kê $(p>0,05)$ so với nghiệm thức NT4(120).

\section{Bảng 3. Tốc độ tăng trưởng của quần thể luân trùng cho ăn với các mật độ tảo khác nhau}

\begin{tabular}{crrrrr}
\hline Ngày nuôi & NT1 $(60)$ & NT2(80) & NT3(100) & NT4(120) & NT5(140) \\
\hline 2 & $0,10 \pm 0,05^{\mathrm{a}}$ & $0,15 \pm 0,08^{\mathrm{a}}$ & $0,10 \pm 0,09^{\mathrm{a}}$ & $0,19 \pm 0,04^{\mathrm{a}}$ & $0,08 \pm 0,06^{\mathrm{a}}$ \\
3 & $0,16 \pm 0,06^{\mathrm{a}}$ & $0,34 \pm 0,05^{\mathrm{c}}$ & $0,28 \pm 0,02^{\mathrm{abc}}$ & $0,29 \pm 0,05^{\mathrm{bc}}$ & $0,20 \pm 0,05^{\mathrm{ab}}$ \\
4 & $0,23 \pm 0,03^{\mathrm{a}}$ & $0,31 \pm 0,03^{\mathrm{a}}$ & $0,28 \pm 0,07^{\mathrm{a}}$ & $0,27 \pm 0,05^{\mathrm{a}}$ & $0,23 \pm 0,05^{\mathrm{a}}$ \\
5 & $0,18 \pm 0,01^{\mathrm{b}}$ & $0,20 \pm 0,02^{\mathrm{b}}$ & $0,19 \pm 0,07^{\mathrm{b}}$ & $0,13 \pm 0,05^{\mathrm{b}}$ & $-0,05 \pm 0,05^{\mathrm{a}}$ \\
6 & $0,13 \pm 0,04^{\mathrm{b}}$ & $0,05 \pm 0,05^{\mathrm{b}}$ & $0,08 \pm 0,07^{\mathrm{b}}$ & $-0,02 \pm 0,07^{\mathrm{b}}$ & $-0,07 \pm 0,08^{\mathrm{a}}$ \\
7 & $0,05 \pm 0,04^{\mathrm{a}}$ & $0,03 \pm 0,03^{\mathrm{a}}$ & $0,05 \pm 0,05^{\mathrm{a}}$ & $-0,02 \pm 0,01^{\mathrm{a}}$ & $-0,06 \pm 0,08^{\mathrm{a}}$ \\
\hline
\end{tabular}

Ghi chú: các kí tư mũ trong cùng hàng có chũ cái khác nhau thì khác biệt có ý nghĩa thống kê (p<0,05). Giá trị trên thể hiện số trung bình và độ lệch chuẩn.

Tốc độ tăng trưởng quần thể cao nhất $(0,34 \%)$ ở $\mathrm{NT2}$ (80) cho ăn 80.000 tb/luân trùng/ngày vào ngày nuôi thứ 3 , cao hơn có ý nghĩa thống kê $(<0,05)$ so với tốc độ tăng trưởng quần thể của luân trùng ở các nghiệm thức còn lại, ngoại trừ cao hơn không có ý nghĩa $(p>0,05)$ so với nghiệm thức $\mathrm{NT3}(100)$ và NT4(120). Từ ngày nuôi thứ 3 đến kết thúc thí nghiệm, tốc độ tăng trưởng càng giảm khi mật độ tảo tăng từ 80.000 tb/luân trùng/ngày đến 140.000 tb/luân trùng/ngày. Luân trùng là loài có vòng đời ngắn từ 4-5 ngày ở nhiệt độ $22^{\circ} \mathrm{C}$ (Kauler \& Enesco,
2011), chúng thường sinh trứng nghỉ khi môi trường nuôi bất lợi như mật độ cá thể tăng lên, thêm vào đó phần trăm quần thể mang trứng giảm xuống (Bảng 4) đã làm cho mật độ không thể phục hồi và giảm dần sau khi đạt mật độ cực đại. Tốc độ tăng trưởng giảm dần và quần thể suy tàn nhanh chóng vào những ngày cuối của chu kì nuôi.

\subsubsection{Phần trăm luân trùng mang trúng}

Phần trăm luân trùng mang trứng của chu kì nuôi dao động từ $4 \%$ - 38\% (Bảng 4 ).

Bảng 4. Phần trăm luân trùng mang trứng $(\%)$ của quần thể luân trùng cho ăn bằng tảo trong quá trình thí nghiệm

\begin{tabular}{crrrrr}
\hline Ngày nuôi & NT1 (60) & NT2 (80) & NT3 (100) & NT4 (120) & NT5 (140) \\
\hline 2 & $36 \pm 11^{\mathrm{a}}$ & $38 \pm 1^{\mathrm{a}}$ & $35 \pm 6^{\mathrm{a}}$ & $20 \pm 13^{\mathrm{a}}$ & $20 \pm 3^{\mathrm{a}}$ \\
3 & $23 \pm 7^{\mathrm{ab}}$ & $34 \pm 10^{\mathrm{b}}$ & $28 \pm 3^{\mathrm{ab}}$ & $17 \pm 1^{\mathrm{ab}}$ & $14 \pm 9^{\mathrm{a}}$ \\
4 & $24 \pm 14^{\mathrm{a}}$ & $38 \pm 14^{\mathrm{a}}$ & $36 \pm 12^{\mathrm{a}}$ & $29 \pm 7^{\mathrm{a}}$ & $21 \pm 4^{\mathrm{a}}$ \\
5 & $10 \pm 6^{\mathrm{a}}$ & $4 \pm 4^{\mathrm{a}}$ & $7 \pm 1^{\mathrm{a}}$ & $11 \pm 10^{\mathrm{a}}$ & $9 \pm 2^{\mathrm{a}}$ \\
6 & $8 \pm 2^{\mathrm{a}}$ & $9 \pm 5^{\mathrm{a}}$ & $7 \pm 1^{\mathrm{a}}$ & $16 \pm 3^{\mathrm{a}}$ & $11 \pm 6^{\mathrm{a}}$ \\
7 & $11 \pm 5^{\mathrm{a}}$ & $16 \pm 13^{\mathrm{a}}$ & $14 \pm 6^{\mathrm{a}}$ & $32 \pm 18^{\mathrm{a}}$ & $37 \pm 16^{\mathrm{a}}$ \\
\hline
\end{tabular}

Ghi chú: các kí tư mũ trong cùng hàng có chũ cái giống nhay thì khác biệt không có ý nghĩa thống kê (p>0,05). Giá trị trên thể hiện số trung bình và độ lệch chuẩn.

Nhìn chung, vào ngày nuôi thứ 2 và thứ 4 , phần trăm luân trùng mang trứng đạt tỷ lệ cao nhất trong chu kì nuôi $38 \%$ và $36 \%$ lần lượt ở nghiệm thức NT2(80) và NT1(60) của ngày ngày nuôi 2 (Bảng 4). Phần trăm con cái mang trứng giảm mạnh từ ngày nuôi thứ 5 cho đến kết thúc thí nghiệm và phần trăm mang trứng cũng giảm khi mật độ tảo tăng từ 80.000 đến 140.000 tb/luân trùng/ngày. Dhert (1996) cho rằng khi nuôi luân trùng ở mật độ càng cao càng làm cho điều kiện nuôi xấu đi, tỉ lệ mang 
trứng giảm mạnh. Theo Hagiwara et al. (1998) khi nước dơ thì độ nhớt của nước tăng lên gây ảnh hưởng đến hoạt động bơi lội, lọc thức ăn và khả năng lấy oxy từ môi trường nước. Do đó, luân trùng không tích lũy đủ năng lượng cho quá trình sinh sản dẫn tỉ lệ mang trứng của luân trùng giảm.

Kết quả của thí nghiệm này khẳng định rằng luân trùng $B$. calyciflorus tăng trưởng mật độ quần thể tốt nhất khi cho ăn bằng tảo Chlorella sp. ở mật độ 80.000 tb/luân trùng/ngày, do vậy mật độ tảo này đã được chọn để tiến hành thí nghiệm thay thế tảo bằng men bánh mì trong nuôi sinh khối luân trùng $B$. calyciflorus.

\section{2. Ảnh hưởng thay thế tảo bằng mem bánh mì lên tăng trưởng quần thể luân trùng Brachionus calyciflorus}

\subsubsection{Các yếu tố môi trường}

Nhiệt độ tương đối ổn định và dao động từ 22,8 ${ }^{\circ} \mathrm{C}-23,1{ }^{\circ} \mathrm{C}$ (Bảng 5). pH nước dao động 8,9 - 9,0. Hai yếu tố nhiệt độ và $\mathrm{pH}$ vẫn nằm trong khoảng thích hợp cho phát triển của luân trùng.
Hàm lượng TAN có xu hướng tăng vào cuối chu kỳ thí nghiệm $(1,32-1,88 \mathrm{mg} / \mathrm{L})$, cao nhất là $1,88 \pm 0,06 \mathrm{mg} / \mathrm{L}$ ở NT4(120T) cho ăn 120.000 tb/luân trùng/ngày vào ngày thứ 6 (Bảng 5 ). Kết quả cho thấy hàm lượng $\mathrm{NH}_{3}$ qua các ngày nuôi và giữa các nghiệm thức nằm trong khoảng thích hợp cho sự phát triển của luân trùng, theo Schlüter and Groeneweg (1985), luân trùng nước ngọt sẽ giảm tăng trưởng khi hàm lượng $\mathrm{NH}_{3}$ trong nước từ 3-5 $\mathrm{mg} / \mathrm{L}$. Hàm lượng TAN tăng lên theo phần trăm men trong khẩu phần ăn tăng và tích tụ dần trong quá trình thí nghiệm, do men bánh mì đa phần sử dụng nguồn carbon làm dinh dưỡng cho sự phát triển tế bào (Xiberras, 2019), thêm vào đó lượng nước cho bể nuôi chỉ được thay $25 \% /$ ngày, đây có thể là nguyên nhân làm cho lượng TAN càng tăng trogn quá trình nuôi. Hàm lượng $\mathrm{NO}_{2}{ }^{-}$trung bình giữa các nghiệm thức, các ngày dao động $0,1-0,9 \mathrm{mg} / \mathrm{L}$ (Bảng 5). Như vậy, chất lượng nước giữa các nghiệm thức thí nghiệm 2 không có sự khác biệt trong quá trình thí nghiệm, luân trùng vẫn có thể phát triển bình thường.

Bảng 5. Các yếu tố môi trường ở thí nghiệm luân trùng Brachionus calyciflorus cho ăn tảo kết hợp men bánh mì

\begin{tabular}{|c|c|c|c|c|c|c|}
\hline \multicolumn{2}{|c|}{ Nghiệm thức } & $\begin{array}{r}\text { NT1 } \\
(100 T) \\
\end{array}$ & $\begin{array}{r}\text { NT2 } \\
(75 T) \\
\end{array}$ & $\begin{array}{r}\text { NT3 } \\
(50 T) \\
\end{array}$ & $\begin{array}{r}\text { NT4 } \\
(25 T) \\
\end{array}$ & $\begin{array}{l}\text { NT5 } \\
\text { (0T) } \\
\end{array}$ \\
\hline \multirow{2}{*}{\multicolumn{2}{|c|}{$\begin{array}{l}\text { Nhiệt độ }\left({ }^{\circ} \mathrm{C}\right) \\
\text { pH }\end{array}$}} & $23,1 \pm 0,2$ & $22,9 \pm 0,1$ & $22,8 \pm 0,1$ & $22,8 \pm 0,2$ & $23,0 \pm 0,2$ \\
\hline & & $8,9 \pm 0,0$ & $8,9 \pm 0,0$ & $8,9 \pm 0,1$ & $8,9 \pm 0,0$ & $9,0 \pm 0,1$ \\
\hline \multirow{2}{*}{$\begin{array}{l}\text { TAN } \\
(\mathrm{mg} / \mathrm{L})\end{array}$} & Ngày 3 & $0,42 \pm 0,10$ & $0,47 \pm 0,13$ & $0,58 \pm 0,07$ & $0,64 \pm 0,07$ & $0,72 \pm 0,07$ \\
\hline & Ngày 6 & $1,32 \pm 0,03$ & $1,47 \pm 0,10$ & $1,59 \pm 0,03$ & $1,88 \pm 0,06$ & $1,79 \pm 0,06$ \\
\hline \multirow{2}{*}{$\begin{array}{l}\mathrm{NO}_{2} \\
(\mathrm{mg} / \mathrm{L})\end{array}$} & Ngày 3 & $0,13 \pm 0,03$ & $0,10 \pm 0,03$ & $0,10 \pm 0,01$ & $0,11 \pm 0,03$ & $0,10 \pm 0,01$ \\
\hline & Ngày 6 & $0,10 \pm 0,01$ & $0,11 \pm 0,01$ & $0,80 \pm 0,01$ & $0,90 \pm 0,01$ & $0,90 \pm 0,01$ \\
\hline
\end{tabular}

\subsubsection{Mật độ phát triển của luân trùng}

Kết quả về mật độ luân trùng trong suốt quá trình thí nghiệm được trình bày trong Bảng 6 .

Luân trùng nuôi từ ngày 02 đến ngày 04 ở nghiệm thức cho ăn tảo kết hợp men bánh mì với tỉ lệ 25\%-50\% (NT2(75T) và NT3(50T)) đạt mật độ luôn cao hơn nghiệm thức NT1(100T) cho ăn hoàn toàn bằng tảo, ngoại trừ mật độ luân trùng ở NT3(50T) ở ngày nuôi thứ 06 thấp hơn mật độ ở NT1(100T), điển hình đó ở ngày nuôi thứ 4 luân trùng ở NT2(75T) và NT3(50T) có mật độ lần lượt là 688 và 747 luân trùng/mL, cao hơn có ý nghĩa thống kê $(\mathrm{p}<0,05)$ so với luân trùng cho ăn $100 \%$ tảo (583 luân trùng $/ \mathrm{mL}$ ). Mật độ luân trùng đạt cao nhất (898 luân trùng/mL) ở nghiệm thức NT2(75T) vào ngày nuôi thứ 5 , cao hơn có ý nghĩa thống kê so với các nghiệm thức còn lại, kế đến là nghiệm thức NT1(100T) là 601 luân trùng $/ \mathrm{mL}$, cao hơn có ý nghĩa thống kê so với mật độ luân trùng ở các nghiệm thức còn lại, ngoại trừ cao hơn không có ý nghĩa thống kê $(\mathrm{p}>0,05)$ so với mật độ luân trùng ở nghiệm thức NT3(50T). Trái lại, mật độ luân trùng giảm khi phần trăm men bánh mì tăng lên trên $75 \%$, ở các nghiệm thức cho ăn từ $100 \%$ men bánh mì thì mật độ luân trùng luôn thấp hơn luân trùng cho ăn hoàn toàn bằng tảo. Ở ngày nuôi thứ 03 luân trùng ở nghiệm thức NT5(0T) có mật độ 222 luân trùng/mL, thấp gần 02 lần so với mật độ luân trùng nuôi bằng tảo, sau đó mật độ luân trùng giảm dần vào các ngày nuôi tiếp theo ở mật độ cho ăn bằng men bánh mì hoàn toàn và chết hoàn toàn ở ngày nuôi thứ 06 . 
Bảng 6. Mật độ của quần thể (luân trùng/mL) cho ăn kết hợp tảo và men bánh mì trong quá trình thí nghiệm

\begin{tabular}{crrrrr}
\hline Ngày nuôi & NT1 (100T) & NT2 (75T) & NT3 (50T) & NT4 (25T) & NT5 (0T) \\
\hline 1 & $200 \pm 0$ & $200 \pm 0$ & $200 \pm 0$ & $200 \pm 0$ & $200 \pm 0$ \\
2 & $245 \pm 24^{\mathrm{ab}}$ & $315 \pm 18^{\mathrm{b}}$ & $315 \pm 51^{\mathrm{b}}$ & $293 \pm 40^{\mathrm{ab}}$ & $219 \pm 18^{\mathrm{a}}$ \\
3 & $420 \pm 30^{\mathrm{ab}}$ & $554 \pm 185^{\mathrm{b}}$ & $653 \pm 27^{\mathrm{b}}$ & $525 \pm 35^{\mathrm{b}}$ & $222 \pm 36^{\mathrm{a}}$ \\
4 & $583 \pm 27^{\mathrm{bc}}$ & $688 \pm 101^{\mathrm{c}}$ & $747 \pm 36^{\mathrm{c}}$ & $461 \pm 90^{\mathrm{b}}$ & $181 \pm 44^{\mathrm{a}}$ \\
5 & $601 \pm 117^{\mathrm{c}}$ & $898 \pm 153^{\mathrm{d}}$ & $449 \pm 20^{\mathrm{bc}}$ & $333 \pm 76^{\mathrm{b}}$ & $35 \pm 18^{\mathrm{a}}$ \\
6 & $502 \pm 36^{\mathrm{b}}$ & $543 \pm 321^{\mathrm{b}}$ & $280 \pm 46^{\mathrm{ab}}$ & $280 \pm 70^{\mathrm{ab}}$ & $0^{\mathrm{a}}$ \\
7 & $350 \pm 63^{\mathrm{c}}$ & $315 \pm 109^{\mathrm{c}}$ & $158 \pm 18^{\mathrm{b}}$ & $140 \pm 18^{\mathrm{ab}}$ & $0^{\mathrm{a}}$ \\
\hline
\end{tabular}

Ghi chú: các kí tụ mũ trong cùng hàng có chũ cái giống nhay thì khác biệt không có ý nghĩa thống kê (p>0,05). Giá trị trên thể hiện số trung bình và độ lệch chuẩn

Hirayama (1987) cho rằng năng suất luân trùng không ổn định và mau tàn khi cho ăn bằng men bánh mì. Theo Sarma et al. (2001), tăng trưởng quần thể của luân trùng nước ngọt $B$. calyciflorus và $B$. patulus cho ăn bằng tảo Chlorella vulgaris tăng trưởng quần thể tốt hơn cho ăn bằng men bánh mì Saccharomyces cerevisiae, khi kết hợp giữa tảo và men bánh mì thì tăng trưởng quần thể của luân trùng thấp hơn so với cho ăn hoàn toàn bằng tảo. Kết quả ở thí nghiệm hiện tại cho thấy khi kết hợp với men từ $25-50 \%$ thì mật độ luân trùng có cải thiện so với cho ăn hoàn toàn bằng tảo hay men bánh mì, điều này đã được chứng minh trên nuôi sinh khối luân trùng Brachionus angularis (Trần Sương Ngọc, 2012).

\subsubsection{Tốc độ tăng trưởng của luân trùng}

Tốc độ tăng trưởng quần thể của luân trùng $B$. calyciflorus trong quá trình thí nghiệm được trình bày trong Bảng 7 .

\section{Bảng 7. Tốc độ tăng trưởng của quần thể luân trùng cho ăn kết hợp tảo và men bánh mì}

\begin{tabular}{crrrrr}
\hline Ngày nuôi & NT1(100T) & NT2(75T) & NT3(50T) & NT4(25T) & NT5(0T) \\
\hline 2 & $0,10 \pm 0,05^{\mathrm{a}}$ & $0,23 \pm 0,03^{\mathrm{a}}$ & $0,22 \pm 0,09^{\mathrm{a}}$ & $0,19 \pm 0,07^{\mathrm{a}}$ & $0,04 \pm 0,04^{\mathrm{a}}$ \\
3 & $0,25 \pm 0,02^{\mathrm{a}}$ & $0,33 \pm 0,11^{\mathrm{b}}$ & $0,39 \pm 0,01^{\mathrm{b}}$ & $0,32 \pm 0,02^{\mathrm{b}}$ & $0,03 \pm 0,05^{\mathrm{ab}}$ \\
4 & $0,27 \pm 0,02^{\mathrm{a}}$ & $0,31 \pm 0,04^{\mathrm{ab}}$ & $0,33 \pm 0,01^{\mathrm{b}}$ & $0,21 \pm 0,02^{\mathrm{ab}}$ & $-0,03 \pm 0,05^{\mathrm{ab}}$ \\
5 & $0,22 \pm 0,02^{\mathrm{b}}$ & $0,30 \pm 0,02^{\mathrm{b}}$ & $0,16 \pm 0,07^{\mathrm{b}}$ & $0,10 \pm 0,05^{\mathrm{b}}$ & $-0,37 \pm 0,02^{\mathrm{a}}$ \\
6 & $0,15 \pm 0,04^{\mathrm{b}}$ & $0,15 \pm 0,05^{\mathrm{ab}}$ & $0,05 \pm 0,07^{\mathrm{b}}$ & $0,05 \pm 0,07^{\mathrm{ab}}$ & - \\
7 & $0,08 \pm 0,04^{\mathrm{a}}$ & $0,06 \pm 0,03^{\mathrm{a}}$ & $-0,03 \pm 0,05^{\mathrm{a}}$ & $-0,05 \pm 0,02^{\mathrm{a}}$ & - \\
\hline
\end{tabular}

Ghi chú: các kí tư mũ trong cùng hàng có chũ cái giống nhay thì khác biệt không có ý nghĩa thống kê (p>0,05)). Giá trị trên thể hiện số trung bình và độ lệch chuẩn. Dấu - biểu thị cho số liệu không theo dõi.

Tốc độ tăng trưởng của luân trùng cao ở ngày đầu của chu kì nuôi do mật độ luân trùng còn thấp, điều kiện môi trường nước nuôi tốt nên tốc độ tăng trưởng của quần thể cao, ngoại trừ luân trùng ở nghiệm thức cho ăn hoàn toàn bằng men bánh mì có tốc độ tăng trưởng giảm dần trong suốt quá trình nuôi do các sản phẩm bài tiết của chúng tích tụ càng nhiều đặc biệt ở các nghiệm thức có phần trăm men cao trong khẩu phần ăn, đây có thể là nguyên nhân đã ảnh hưởng đến quá trình sinh sản và phát triển của quần thể, tốc độ tăng trưởng giảm dần dẫn đến quần thể suy tàn nhanh chóng vào những ngày cuối của chu kì nuôi. Tốc độ tăng trưởng ở nghiệm thức cho ăn bằng khẩu phần ăn kết hợp giữa tảo và men bánh mì từ $25-75 \%$ vào ngày nuôi thứ 3 dao động từ $0,32-0,39 \%$ cao hơn có ý nghĩa $(\mathrm{p}<0,05)$ so với nghiệm thức cho ăn hoàn toàn bằng tảo, ngoại trừ nghiệm thức cho ăn từ $100 \%$ men (đạt $0,03 \%$ ) thấp hơn so với luân trùng cho ăn hoàn toàn bằng tảo. Ở ngày nuôi thứ 4 thì tốc độ tăng trưởng quần thể luân trùng ở nghiệm thức $\mathrm{NT2}(75 \mathrm{~T})$ và $\mathrm{NT} 3(50 \mathrm{~T})$ lần lượt là 0,31 và $0,33 \%$, vẫn cao hơn luân trùng cho ăn hoàn toàn bằng tảo, trong đó tốc độ tăng trưởng quần thể ở NT3(50T) cao hơn có ý nghĩa $(\mathrm{p}<0,05)$ so với nghiệm thức cho ăn hoàn toàn bằng tảo. Từ ngày nuôi thứ 05 thì tốc độ tăng trưởng của quần thể luân trùng ở các nghiệm thức cho ăn kết hợp với men bánh mì thấp hơn luân trùng cho ăn hoàn toàn bằng tảo $(\mathrm{p}>0,05)$ so với tốc độ tăng trưởng của quần thể cho ăn hoàn toàn bằng tảo. Sau đó tốc độ tăng trưởng quần thể ở các nghiệm thức giảm mạnh, quần thể có tăng trưởng âm ở quần thể cho ăn kết hợp $50 \%$ men $(-0,03 \%)$ và $75 \%$ men $(-0,05 \%)$, ngược lại tốc độ tăng trưởng quần thể ở nghiệm thức cho ăn kết hợp bằng men bánh mì $25 \%$ chỉ đạt $0,06 \%$, thấp hơn không có ý nghĩa thống kê so tốc độ tăng trưởng của luân trùng cho ăn hoàn toàn bằng tảo $(0,08 \%)$. Nhìn chung, nếu so sánh với luân trùng cho ăn hoàn toàn 
bằng tảo thì tốc độ tăng trưởng quần thể của luân trùng cho ăn bằng tảo kết hợp với men bánh mì với tỉ lệ 50:50 cao hơn.

\subsubsection{Phần trăm luân trùng mang trứng}

Phần trăm luân trùng mang trứng trong quần thể cao hơn ở các NT cho ăn kết hợp tảo và men bánh mì so với các nghiệm thức khác (Bảng 8).

Bảng 8. Phần trăm mang trứng $(\%)$ của quần thể luân trùng cho ăn bằng men và tảo

\begin{tabular}{crrrrr}
\hline Ngày nuôi & NT1 $(100 T)$ & NT2(75T) & NT3(50T) & NT4(25T) & NT5(0T) \\
\hline 2 & $21 \pm 10^{\mathrm{a}}$ & $23 \pm 8^{\mathrm{a}}$ & $24 \pm 4^{\mathrm{a}}$ & $19 \pm 6^{\mathrm{a}}$ & $17 \pm 13^{\mathrm{a}}$ \\
3 & $29 \pm 10^{\mathrm{a}}$ & $30 \pm 9^{\mathrm{a}}$ & $26 \pm 1^{\mathrm{a}}$ & $16 \pm 14^{\mathrm{a}}$ & $18 \pm 11^{\mathrm{a}}$ \\
4 & $29 \pm 10^{\mathrm{a}}$ & $33 \pm 14^{\mathrm{a}}$ & $25 \pm 5^{\mathrm{a}}$ & $25 \pm 7^{\mathrm{a}}$ & $15 \pm 14^{\mathrm{a}}$ \\
5 & $23 \pm 11^{\mathrm{b}}$ & $15 \pm 8^{\mathrm{b}}$ & $16 \pm 5^{\mathrm{b}}$ & $24 \pm 8^{\mathrm{b}}$ & $0^{\mathrm{a}}$ \\
6 & $7 \pm 3^{\mathrm{b}}$ & $7 \pm 2^{\mathrm{b}}$ & $20 \pm 5^{\mathrm{b}}$ & $18 \pm 10^{\mathrm{b}}$ & - \\
7 & $10 \pm 9^{\mathrm{b}}$ & $11 \pm 7^{\mathrm{b}}$ & $22 \pm 10^{\mathrm{b}}$ & $16 \pm 5^{\mathrm{b}}$ & - \\
\hline
\end{tabular}

Ghi chú: các kí tụ mũ trong cùng hàng có chũ cái giống nhay thì khác biệt không có ý nghĩa thống kê (p>0,05). Giá trị trên thể hiện số trung bình và độ lệch chuẩn. Dấu - biểu thị cho số liệu không theo dõi.

Ở ngày thứ 4 , phần trăm luân trùng mang trứng ở nghiệm thức NT2(75T) cho ăn 75\% tảo kết hợp $25 \%$ men bánh mì đạt 33\% (Bảng 7) cao hơn không có ý nghĩa thống kê $(\mathrm{p}>0,05)$ với các $\mathrm{NT}$ còn lại. Nhìn chung, tî̉ lệ mang trứng của quần thể luân trùng có sự khác biệt giữa các nghiệm thức, gia tăng theo sự giảm tỉ lệ men cho ăn. Nước nuôi luân trùng bằng men bánh mỳ thường khá dơ và tạo hạt, có thể làm cho độ nhớt của nước tăng lên. Theo Hagiwara et al. (1998), độ nhớt của nước tăng lên gây ảnh hưởng đến hoạt động bơi lội, lọc thức và khả năng lấy oxy từ môi trường nước, đây có thể là nguyên nhân luân trùng ở các nghiệm thức cho ăn với men bánh mì với liều cao thường có phần trăm con mang trứng trong quần thể thấp hơn so với nuôi bằng tảo.

\section{KẾT LUẬN VÀ ĐỀ XUẤT}

Tăng trưởng quần thể của luân trùng Brachionus calyciflorus bị ảnh hưởng đến mật độ tảo trong môi trường nuôi, mật độ đạt cao nhất (688 luân trùng/mL) khi cho ăn 80.000 tế bào/luân trùng/ngày.

Quần thể luân trùng $B$. calyciflorus giảm dần khi cho ăn hoàn toàn bằng men bánh mỳ, nhưng khi thay 25\%-50\% tảo Chlorella bằng men bánh mỳ thì tăng trưởng quần quần thể luân trùng $B$. calyciflorus có cải thiện, mật độ đạt 898 luân trùng/mL và 747 luân trùng $/ \mathrm{mL}$, cao hơn cho ăn hoàn toàn bằng tảo.

Nên tiến hành nuôi sinh khối luân trùng $B$. calyciflorus với mật độ tảo là 80.000 tb/luân trùng $/ \mathrm{mL}$ và có thể thay thế $25-50 \%$ tảo bằng men bánh mì để đạt tăng trưởng quần thể tốt hơn và tiết kiệm diện tích cho nuôi cấy tảo.

\section{LỜI CẢM TẠ}

Nhóm tác giả chân thành cảm ơn sinh viên Bùi Diễm Thanh, lớp Nuôi trồng thủy sản khóa 42 đã giúp đỡ trong bố trí thí nghiệm và thu thập số liệu.

\section{TÀI LIỆU THAM KHẢO}

Arak, G. V., Satish, Dr., \& Mokashe, S. (2014). Potential of fresh water rotifer, B. calyciflorus as live feed. International Journal of Science and Research (IJSR), 4(10), 2319-7064.

Awaiss, A., \& Kestemont, P. (1998). Feeding sequences (rotifer and dry diet), survival, growth and biochemical composition of African catfish, Clarias gariepinus Burchell (Pisces: Clariidae), larvae. Aquaculture Research, 29(10), 731-741.

Chen, J., Wang, Z., Li, G., \& Guo, R. (2014). The swimming speed alteration of two freshwater rotifers Brachionus calyciflorus and Asplanchna brightwelli under dimethoate stress. Chemosphere, 95, 256-260.

Chen, W., Liu, H., Zhang, Q., \& Dai, S. (2011). Effects of nitrite and toxic Microcystis aeruginosa PCC7806 on the growth of freshwater rotifer Brachionus calyciflorus. Bulletin of Environmental Contamination and Toxicology, 86(3), 263-267.

Dhert, P., 1996. Rotifers. In Sorgeloos, P., Lavens, P. (Eds.), Manual on the production and use of live food for aquaculture. Fisheries technical paper no.361(pp: 49-78). Food and Agriculture Organization of the United Nation, Rome.

Hagiwara, A., Yamamiya, N., \& Belem de Araujo, A. (1998). Effect of water viscosity on the population growth of the rotifer Brachionus plicatilis Müller. Hydrobiologia, 387, 489-494.

Hirayama, K. (1987). A consideration of why mass culture of the rotifer Brachionus plicatilis with baker's yeast is unstable. Hydrobiologia , (147), 269-270.

Kauler, P., \& Enesco, H. E. (2011). The effect of temperature on life history parameters and cost of reproduction in the rotifer Brachionus calyciflorus. Journal of Freshwater Ecology, 26(3), 399-408. 
Komis A. (1992). Improve production and utilization of the rotifer Brachionus plicatilis Muller, in European sea bream (Sparus aurata Linnaeus) and sea bass (Dicentrachus labrax Linnaeus) larviculture ( $\mathrm{PhD}$ thesis). University of Gent.

Liang, Y., Shao, L., Jiang, Q., \& Yang, J. (2019). Changes in the life-cycle parameters and glutathione-related antioxidant defense system of rotifer Brachionus calyciflorus under the combined stress of microcystin-LR and ammonia. Aquatic Ecology, 54, 243-256.

Lim, L. C., \& Wong, C. C. (1997). Use of the rotifer, Brachionus calyciflorus Pallas, in freshwater ornamental fish larviculture. Hydrobiologia, 358(1/3), 269-273.

Lucía-Pavón, E., Sarma, S. S. S., \& Nandini, S. (2001). Effect of different densities of live and dead Chlorella vulgaris on the population growth of rotifers Brachionus calyciflorus and Brachionus patulus (Rotifera). Revista de Biología Tropical, 49(3-4), 895-902

Mitchell, S. A. (1992). The effect of $\mathrm{pH}$ on Brachionus calyciflorus Pallas (Rotifera). Hydrobiologia, 245(2), 87-93.

Rufchaie, R., Kapourchali, M. F., Armoudli, R.; Azizzadeh, L., Salavatian, M., Chubian, F., \& Pajand, Z. (2012). Potential to use the native freshwater rotifer, Brachionus calyciflorus in feeding Acipenser persicus larvae. Annals of Biological Research, 3(2), 965-974.

Sarma, S.S.S., Larios Jurado, P. S., \& Nandini, S. (2001). Effect of three food types on the population growth of Brachionus calyciflorus and Brachionus patulus (Rotifera:

Brachionidae). Revista de Biología Tropical, 49(1), 77-84.

Schlüter, M., \& Groeneweg, J. (1985). The inhibition by ammonia of population growth of the rotifer, Brachionus rubens, in continuous culture. Aquaculture, 46(3), 215-220.

Stevenson, R. A. A., Sarma, S. S. S., \& Nandini, S. (1998). Population dynamics of Brachionus calyciflorus (Rotifera: Brachionidae) in waste water from food-processing industry in Mexico. Revista de Biología Tropical, 46(3), 595-600.

Trần Sương Ngọc (2012). Nghiên cứu đặc điểm sinh học, nuôi và sử dụng luân trùng nước ngọt (Brachionus angularis) (Luận án tiến sỹ Thủy sản). Đại Học Cần Thơ.

Trần Sương Ngọc (2017). Giáo trình kỹ thuật nuôi thức ăn tụ nhiên. Giáo trình Trường Đại Học Cần Thơ

Trần Sương Ngọc, Nguyễn Thành Đức, Nguyễn Tấn Khương, \& Vũ Ngọc Út. (2010). Ảnh hưởng của tảo Chlorella và men bánh mì lên sự phát triển của quần thể luân trùng nước ngọt (Brachionus angularis) nuôi trên bể. Tạp chí khoa học, Truòng Đại hoc Cần Tho, 4b, 66-75.

Xiberras, J., Klein, M., \& Nevoigt, E. (2019). Glycerol as a substrate for Saccharomyces cerevisiae based bioprocesses Knowledge gaps regarding the central carbon catabolism of this "non-fermentable" carbon source. Biotechnology Advances, 37, 1-15. 